\title{
The future of male contraception: a fertile ground
}

\author{
Iyad Khourdaji ${ }^{1}$, Jacqueline Zillioux ${ }^{1}$, Kevin Eisenfrats ${ }^{2}$, Daniel Foley ${ }^{3}$, Ryan Smith ${ }^{1,2,3}$ \\ ${ }^{1}$ Department of Urology, University of Virginia Healthcare System, Charlottesville, VA, USA; ${ }^{2}$ Contraline, Inc., Charlottesville, VA, USA; \\ ${ }^{3}$ University of Virginia School of Medicine, Charlottesville, VA, USA \\ Contributions: (I) Conception and design: I Khourdaji, J Zillioux, R Smith; (II) Administrative support: R Smith; (III) Provision of study materials \\ or patients: None; (IV) Collection and assembly of data: I Khourdaji, J Zillioux; (V) Data analysis and interpretation: All authors; (VI) Manuscript \\ writing: All authors; (VII) Final approval of manuscript: All authors. \\ Correspondence to: Iyad Khourdaji. Department of Urology, University of Virginia, PO Box 800422, Charlottesville, VA 22908-0422, USA. \\ Email: akhourdaji@gmail.com.
}

\begin{abstract}
The continued and rapid expansion of the Earth's population mandates the need for safe and effective measures of contraception. While a plethora of options exist for women, methods of contraception for the male partner are limited to condoms and vasectomy. The sequela of this discrepancy has led to the family planning burden falling disproportionately on the female partner. For the past several decades, extensive research has been undertaken exploring the feasibility of hormonal male contraception. This proposed method of contraception has focused on suppressing spermatogenesis by exploiting the hypothalamic-pituitary-gonadal (HPG) axis. Beginning with proof of concept studies in the early nineties, administration of testosterone in healthy male subjects has been shown to be an efficacious method of inducing sterility. Owing to ethnic differences in spermatogenesis suppression and the comparatively low rate of azoospermia in Caucasian men with androgen-only regimens, investigators have explored the addition of progestins to further enhance the efficacy of hormonal contraception. Though studies have revealed promise with androgen-progestin regimens, the lack of long-term studies has precluded the development of a marketable product. Recently, more research has been directed towards identifying non-hormonal alternatives to male contraception. These non-hormonal options have ranged from the development of devices facilitating reversible occlusion of the vas deferens lumen to medications disrupting various pathways in the process of spermatogenesis. Underlying the development of hormonal and non-hormonal strategies is the shared enthusiasm men and women have towards these male directed methods. The willingness of couples to pursue these alternatives combined with the global need to reduce the psychological and socioeconomic implications of unintended pregnancy ensures that research will continue to bring this goal to fruition.
\end{abstract}

Keywords: Male hormonal contraception; non-hormonal contraception; pregnancy rate; azoospermia; androgenprogestin combination therapy; vas deferens occlusion

Submitted Mar 13, 2018. Accepted for publication Mar 23, 2018.

doi: $10.21037 /$ tau.2018.03.23

View this article at: http://dx.doi.org/10.21037/tau.2018.03.23

\section{Introduction}

Currently, the world population is increasing at a rate of 80 million persons per year and is projected to exceed 9 billion by 2050 (1). Moreover, it is estimated that nearly half of all pregnancies worldwide are unplanned (2). Given this rapid growth, unintended pregnancy has drastic psychological and socioeconomic implications (3). The cost of unintended pregnancy in the United States alone is estimated to be approximately 15 billion dollars. The rapid rate of population growth and the astounding number of unintended pregnancies are at least partly attributed to the lack of access to adequate contraception $(1,4)$. The availability of numerous, effective and 
reversible contraceptive choices for women has led to the female partner unequivocally shouldering the primary responsibility for family planning (5). While these options have been available to women for the past 50 years, male options have remained limited (6). In this article, we review the current status of male contraception focusing on male hormonal contraception, non-hormonal systemic contraception as well as vas deferens occlusion devices.

\section{Current methods of male contraception}

Current methods of male contraception include condoms and vasectomy but are not ideal due to high failure rate and difficult reversibility, respectively $(2,7)$. Overall, $25 \%$ of contraception worldwide relies on these maledirected methods (2). The condom is the oldest method of contraception used by $5.7 \%$ of couples worldwide (8). In the United States, $30 \%$ of couples use male methods alone for contraception with at least $10 \%$ of these couples relying on condoms. While offering protection against sexually transmitted diseases, the failure of condoms is estimated to be between $15-18 \%$ with typical use (8-10). Even with perfect use, the failure rate of condoms is reported to be $3 \%$ (11). Moreover, the long-term use of condoms is generally low, as $57 \%$ of men discontinue use within the first year $(12,13)$.

Meanwhile, vasectomy is considered a permanent method of male contraception utilized by $2.7 \%$ of couples seeking contraception. In the United States, $6-13 \%$ of couples select vasectomy $(8,14,15)$. The prevalence of vasectomy varies considerably depending on cultural factors and healthcare though in the US approximately 500,000 men per year undergo this procedure (14). In some economically developed countries, vasectomy is practiced more widely; however worldwide female sterilization occurs approximately 4 times more frequently (16). Though highly effective with an efficacy rate greater than $99 \%$, vasectomy requires a surgical procedure that is not without its inherent risks. These risks include bleeding, infection, chronic orchialgia, granuloma formation and recanalization $(8,17)$. Furthermore, vasectomy reversal is a much more challenging procedure that is often cost-prohibitive with no guarantee of success $(8,11,17)$.

\section{Basis for the hormonal approach}

Given the poor efficacy and compliance of condoms and the risks, costs and challenging reversibility of vasectomies, research in the arena of male contraception has focused on the development of hormonal methods of achieving sterility. The development of male hormonal contraception has been predicated upon several criteria describing the ideal form of contraception. These criteria state that male contraceptives are required to be (I) as effective and safe as female methods with a fast onset of infertility and complete restoration of fertility after withdrawal, (II) free of negative effects on offspring and (III) financially affordable, non-obtrusive and convenient $(18,19)$.

Attitudes amongst men regarding fertility control have further encouraged research in the field of male hormonal contraception. In a survey of 9,000 males aged 18-50 years in nine countries on four continents, Heinemann et al. found that the majority of men would accept the notion of a male hormonal contraceptive. Though acceptance varied widely based on nationality, greater than $55 \%$ of men surveyed would be amenable to male hormonal contraception (MHC) (20). Furthermore, women also appear to be in favor of hormonal methods of male contraception. In a survey of 1,894 women presenting to family planning clinics in Scotland, South Africa and Shanghai, $65 \%$ felt that women unequivocally shouldered the contraceptive burden. In addition, up to $90 \%$ of Scottish and South African women were in favor of male hormonal contraception with response less positive in Chinese women $(\sim 79 \%)(21,22)$.

That MHC would fulfill many of the aforementioned criteria of an ideal form of contraception and has the support of many men worldwide has leads to significant research and development in this field. Mechanistically, the goal of MHC is the reversible suppression of spermatogenesis to levels consistent with infertility via suppression of testicular Leydig and Sertoli cell function (23). Through this method, investigations undertaken over the past four decades have shown that MHC can result in suppression of spermatogenesis with subsequent prevention of pregnancy though a commercial product remains unavailable (24). Nevertheless, MHC provides men and women the opportunity to share the burden of family planning while simultaneously satisfying important individual and societal needs (25).

\section{The HPG axis and mechanism for MHC}

Starting in the late 1970s, investigation of a hormonal approach to male contraception was founded on data demonstrating the pivotal role of testosterone in spermatogenesis (26). Research from this era demonstrated 
the importance of Leydig cells in the secretion of testosterone and the subsequent maintenance of both systemic and intratesticular levels of testosterone. Moreover, Leydig cells were shown to play a major role in supporting spermatogenesis leading to development of contraceptive strategies aiming to disrupt the HPG axis (27).

Briefly, the HPG axis describes the complex process in which the secretion of hormones from the hypothalamus and pituitary stimulate the testes to produce testosterone and sperm. This process begins with the pulsatile release of gonadotropin-releasing hormone $(\mathrm{GnRH})$ from the hypothalamus. GnRH acts upon the anterior pituitary gland stimulating the release of the gonadotropins, luteinizing hormone $(\mathrm{LH})$ and follicle-stimulating hormone (FSH) (18). LH binds to Leydig cells in the testicular interstitium resulting in the production of testosterone while spermatogenesis is mediated by FSH acting on Sertoli cells. Testosterone produced by Leydig cells is released systemically and intratesticularly. However, intratesticular testosterone concentrations are 100-200 times greater than that measured in serum thus promoting an ideal environment for spermatogenesis within the seminiferous tubules $(1,11)$. The development of MHC has hinged upon the negative-feedback circulating testosterone has on the hypothalamus and pituitary gland. By down-regulating the release of gonadotropins, the process of spermatogenesis is suppressed thereby theoretically providing a method of contraception. Through this method of suppression, an interval of 2-3 months would be required for male hormonal contraceptives to reach their full effect, similar to the time necessary for vasectomy to become fully effective (28).

\section{Male hormonal contraception}

\section{Androgen-only regimens}

Investigation into MHC and the use of androgens to facilitate hormonal male contraception began at the National Institute of Health (NIH) in the 1970s. The NIH was able to demonstrate the efficacy of IM testosterone in markedly suppressing spermatogenesis with a favorable side effect profile (29). This was subsequently followed by a landmark study produced by the World Health Organization (WHO). In this multicenter, international investigation, the efficacy of hormonally-induced azoospermia in 271 healthy fertile men was researched. Each patient received $200 \mathrm{mg}$ weekly injections of testosterone enanthate (TE). At 6 months, $65 \%$ of men became azoospermic. After following these azoospermic men for 12 months, there was an observed rate of 0.8 conceptions per 100 person years. Overall, the mean time to azoospermia was 120 days with median time to recovery of a sperm concentration of at least 20 million/mL being 3.7 months (30). In essence, the NIH and WHO studies provided proof of concept data on the use of androgens to achieve hormonal contraception.

The WHO continued to explore the feasibility of MHC in 1996 with another international prospective study involving 15 centers in nine countries. Again the investigators studied the efficacy of weekly injections of $200 \mathrm{mg}$ TE on inducing sperm suppression to severe oligozoospermia or azoospermia. In this study of 399 normal, healthy and fertile men, pregnancy rates of $8.1 \%$ and $0 \%$ per 100 person-years were observed for patients achieving severe oligozoospermia and azoospermia, respectively. The standout data from this study was the significant number of pregnancies achieved despite patients being rendered severely oligoozospermic (31). Based on this study, the cutoff to achieve durable and reversible contraception was deemed to be a sperm concentration of less than 3 million $/ \mathrm{mL}$. Since then, however, the consensus of summit meetings on male hormonal contraception has advocated a tighter definition of severe oligozoospermia to a sperm concentration of $\leq 1 \mathrm{million} / \mathrm{mL}$ (32).

The preliminary $\mathrm{WHO}$ data led to further studies assessing the efficacy of testosterone in MHC. In 17 healthy Thai men, Sukcharoen et al. investigated the contraceptive efficacy of weekly injections of $200 \mathrm{mg}$ TE. The median time to azoospermia was 85 days. In a total of 152 months of exposure, no pregnancies were experienced in men who achieved azoospermia. In the three men who entered the efficacy phase while oligozoospermic (concentrations $>3$ million $/ \mathrm{mL}$ ), no pregnancies were experienced during the six months of exposure (33).

MacIndoe $e t$ al. randomized men to receive injections of testosterone cypionate (TC) ranging from doses of 100 , 250 or $500 \mathrm{mg} / \mathrm{wk}$. Prior to and concluding treatment with TC, the subjects received an identically appearing TC placebo for two and twelve weeks, respectively. The authors discovered that spermatogenesis was indeed impaired by TC but the decrease in sperm count was not strictly dose dependent. FSH and LH levels ultimately fell to undetectable levels at a dose-dependent rate with complete suppression occurring after two weeks with the 250 and $500 \mathrm{mg} / \mathrm{wk}$ doses and after six weeks with the $100 \mathrm{mg} / \mathrm{wk}$ dose. After cessation of treatment, all TC-mediated influences on the hypothalamic-pituitary-testicular axis 
were reversed (34).

Though researchers have identified fairly predictable responses to $\mathrm{MHC}$ with $\mathrm{T}$, ethnic differences have also been uncovered $(9,35,36)$. In two large, prospective Chinese studies published by Gu et al. depot injections of testosterone undecanoate ( $\mathrm{TU}$ ) were observed to elicit more pronounced suppression in subjects compared to the results of the original WHO trial. First, Gu et al. administered monthly injections of $500 \mathrm{mg}$ TU in a study of 308 healthy Chinese men. In this study, the subjects underwent a 12 -month control period followed by a 6-month suppression phase during which a $1,000 \mathrm{mg}$ loading dose of TU was injected. The patients were then observed for a 6-month efficacy phase followed by a 12 -month recovery period. During the suppression phase, $2.92 \%$ of men failed to achieve azoospermia or severe oligozoospermia. In subjects adequately suppressed, there were no pregnancies in the efficacy phase. A secondary failure rate of 2.3/100 couple years was demonstrated attributed to the reappearance of sperm in six men with one couple experiencing a pregnancy due to sperm rebound. Overall, the total failure rate was $5.2 \%$ and total efficacy was $94.8 \%$ with spermatogenesis returning to the normal reference range within the recovery period (35).

In a multicenter, phase III clinical trial, Gu et al. further studied the effects of IM injections of $500 \mathrm{mg}$ of TU on 1,045 Chinese men. A cumulative failure rate of 1.1 per 100 men was observed. $4.8 \%$ of men experienced inadequate suppression with an additional $1.3 \%$ experiencing postsuppression sperm rebound. In the 24-month efficacy phase, 9 pregnancies were experienced in 1,554 person-years of exposure. After cessation of therapy, spermatogenesis returned to the normal fertile reference range in all but two participants (36).

The results of the Gu et al. trials certainly highlighted the potential for ethnic differences in suppression of spermatogenesis with hormonal therapy. In the above studies, an azoospermic rate as high as $93 \%$ was achieved at the end of the 6-month suppression phase, which was much greater than that seen in the landmark WHO trials where an azoospermic rate of $64.5 \%$ was observed $(9,35,36)$.

Recognizing that the hormonal contraception studies have included only men with normal semen parameters prior to administration of therapy, Nieschlag et al. investigated how men with subnormal semen parameters ( $\leq 20$ million) would respond to hormonal male contraception. Subjects with normal $(n=23)$ and subnormal $(n=18)$ were enrolled into a 34-week treatment phase where they received four injections of $1,000 \mathrm{mg}$ TU in weeks $0,6,14$ and $24.73 \%$ and $72 \%$ of the men with normal and abnormal pretreatment parameters experienced suppression of sperm counts to less than 1 million/ejaculate, respectively. Furthermore, all men regardless of normal or subnormal pre-treatment sperm counts experienced full recovery of sperm counts to pre-treatment levels. Overall, the total rate of successful suppression of spermatogenesis did not differ between the groups with a slightly higher percentage of men in the normal group achieving azoospermia (56\% vs. 44\%) (37).

\section{Combined treatment: androgens and progestins}

While studies utilizing $\mathrm{T}$ to establish $\mathrm{MHC}$ have shown promise, investigators have assessed the use of combination regimens utilizing $\mathrm{T}$ and progestins to more efficaciously suppress sperm production. Providing the impetus for this research has been the observation that while $95 \%$ of Caucasian men suppress sperm concentrations to at least $\leq 3 \mathrm{million} / \mathrm{mL}$ with $\mathrm{T}$ treatment alone, only approximately $65 \%$ achieve azoospermia (38-40). Moreover, in order to achieve clinically meaningful suppression of spermatogenesis, suppression of LH and FSH should be to levels of $\leq 0.5 \mathrm{IU} / \mathrm{mL}(39,41)$. Progestins enhance the suppressive effect of androgens on spermatogenesis likely though increased inhibition at the level of the pituitary and hypothalamus (42). An analysis by McLachlan et al. found that complete suppression of $\mathrm{LH}$ and intratesticular $\mathrm{T}$ levels provides for the most effective male hormonal contraception with suppression further enhanced by the addition of progestins via gonadotropin-independent mechanisms (39).

An initial application of achieving androgen-progestin contraception in men was studied by Meriggiola et al. when the efficacy of a low dose progestin coupled with $\mathrm{TE}$ on suppression of spermatogenesis and gonadotropins was investigated. In this study, ten healthy men received cyproterone acetate (CPA) at a dose of 25 or $12.5 \mathrm{mg} /$ day along with $100 / \mathrm{mg}$ of TE for a total of 16 weeks. All five men in the group receiving $25 \mathrm{mg}$ of CPA achieved azoospermia after $9.0 \pm 1.3$ weeks. Three men in the group receiving $12.5 \mathrm{mg}$ CPA achieved azoospermia after $8.7 \pm 0.7$ weeks. Gonadotropins were suppressed to the minimum level of detection by the assay used in the study. Certainly limited by small population size, Meriggiola et al. identified promise in this combined regimen (43).

In another study limited by its size but that shed further 
promise on the notion of combined progestin-androgen therapy, Buchter et al. studied the efficacy of achieving hormonal contraception utilizing a combined regimen of oral levonorgestrel (LNG) and transdermal T. Specifically, patients were given $250 \mu \mathrm{g}$ of oral LNG up to week 12, which was increased to $500 \mu \mathrm{g}$ in those not achieving azoospermia, and $328 \mathrm{mg}$ of transdermal $\mathrm{T}$. Eleven patients were enrolled in the study. Within 24 weeks, two patients had become azoospermic with an additional three patients demonstrating sperm concentrations below 3 million/mL. The remaining six patients failed to reach suppression adequate enough for spermatogenesis (44).

Martin et al. investigated the contraceptive efficacy of combined oral desogestrel and testosterone pellets in thirty healthy male subjects. Patients were equally assigned to receive desogestrel doses of 75, 150 and $300 \mu \mathrm{g}$ along with a subcutaneous $300 \mathrm{mg}$ testosterone implant. Sperm concentrations fell in a dose-dependent manner, with three men, one man and seven men in the three groups achieving severe oligozoospermia $\left(<3 \times 10^{6} / \mathrm{mL}\right)$, respectively. Three men achieved azoospermia in the $300 \mu \mathrm{g}$ group (45).

Turner et al. investigated the efficacy of a combination of depot medroxyprogesterone acetate (DMPA) with testosterone implants at regular intervals. Fifty-five healthy men in stable fertile relationships were given four 200-mg testosterone implants placed every 4 to 6 months along with a $300 \mathrm{mg}$ DMPA injection every 3 months. In 426 person-months, no pregnancies occurred and by 3 months, $94 \%$ of men had successfully suppressed spermatogenesis to below $1 \mathrm{million} / \mathrm{mL}$. After cessation of therapy, sperm concentration reached 20 million sperm/mL by a median of 5 months. Of note, the authors found that a few men treated with testosterone implants at 6-month intervals experienced androgen deficiency symptoms and/or escape of gonadotropin and spermatogenic suppression between months 5 and 6 . These men were subsequently managed with testosterone implants every 4 months instead (46).

In a study of 112 healthy male volunteers, Hay et al. administered a novel combination of oral etonogestrel (ENG) and intramuscular testosterone decanoate (TD). The subjects were randomized to receive $300 \mu \mathrm{g}$ ENG daily and $400 \mathrm{mg}$ TD every 4 or 6 weeks for a total of 48 weeks. After 48 weeks, all but one man experienced suppression of sperm concentration to less than 1 million $/ \mathrm{mL}$ with faster suppression occurring in the 4-week group. At 48 weeks, no significant difference between treatment groups in regards to suppression of spermatogenesis. When assessing the groups individually, the 4-week group achieved severe oligozoospermia of less than $1 \mathrm{M} / \mathrm{mL}$ in 98 and $100 \%$ of subjects and azoospermia in 70 and $95.3 \%$ after 24 and 48 weeks of treatment, respectively. Furthermore, gonadotropins were noted to be suppressed in both groups with suppression less pronounced in the 6-week group. In this group, LH and FSH levels were found to be above the lower limits of detection in all subjects who failed to suppress sperm concentration below $3 \mathrm{M} / \mathrm{mL}$ at 24 weeks. The median time to recovery was found to be 16 weeks with recovery occurring faster in the 6-week treatment group though mean sperm densities were lower than that observed at baseline. The discrepancy between baseline and posttreatment sperm densities was considered to be artificial due to cessation of follow-up after achieving a concentration of at least 20 million/mL (47).

In a randomized-controlled, double-blind, multicenter study, Mommers et al. assigned 54 healthy men to receive either a low or high-release ENG subcutaneous implant with intramuscular TU injections or placebo implant and injections. TU dose was either $750 \mathrm{mg}$ every 10 or 12 weeks or $1,000 \mathrm{mg}$ every 12 weeks for 44 weeks. After 16 weeks, $89 \%$ suppressed spermatogenesis to 1 million $/ \mathrm{mL}$ or less, which was enhanced to $94 \%$ in the high-release ENG groups. High-release ENG implant along with TU at doses of $750 \mathrm{mg}$ every 10 weeks and $1,000 \mathrm{mg}$ every 12 weeks achieved suppression of $93 \%$ and $95 \%$, respectively. Suppression was maintained for the entire treatment period in $91 \%$ of men with $3 \%$ of men never achieving suppression below 1 million/mL. After cessation of therapy, the median time to recovery of spermatogenesis to 20 million/mL was 15 weeks (48).

Roth et al. studied the efficacy of hormonal contraception utilizing transdermal testosterone and Nestorone (NES) in 99 healthy subjects. Patients were randomized to one of three treatment groups including $10 \mathrm{~g}$ of $\mathrm{T}$ gel with varying doses of NES or NES placebo. In the 69 patients completing at least 20 weeks of treatment, nearly $89 \%$ of men achieved suppression of sperm concentration down to less than or equal to 1 million spermatozoa/mL. Moreover, the investigators discovered that serum gonadotropin levels after 4 weeks of therapy were strongly predictive (96\%) of failure to suppress spermatogenesis after 20-24 weeks (49).

Page $e t a l$. studied the combined regimen of testosterone gel (T gel), depot medroxyprogesterone acetate (DMPA) and the GnRH antagonist, acyline, to determine if the addition of a GnRH antagonist would result in an accelerated rate of spermatogenesis suppression. Forty-four healthy men were randomized to $100 \mathrm{mg}$ of daily $\mathrm{T}$ gel with 
DMPA (300 mg every 3 months) or T gel and DMPA with acyline. In the 38 men that completed the 24-week study, $90 \%$ of subjects became severely oligospermic; however, the addition of acyline did not enhance nor expedite this process (50).

Behre et al. recently studied the use of intramuscular injections of norethisterone enanthate (NET-EN) combined with TU in 320 healthy men. At doses of NET-EN and TU of $200 \mathrm{mg}$ and $1,000 \mathrm{mg}$, respectively, administered every 8 weeks, 274 men experienced suppression of spermatogenesis to a concentration of $\leq 1$ million $/ \mathrm{mL}$ by the end of 24 weeks. A pregnancy rate of 1.57 per 100 users was observed in the 266 men who entered the efficacy phase. After 52 weeks, $94.8 \%$ of men exhibited recovery of spermatogenesis to a concentration of $\geq 15$ million $/ \mathrm{mL}$ (24).

\section{Investigating the difference between androgen alone versus combination therapy}

The data regarding MHC facilitated with an androgen alone or combined with a progestin led to Ly et al. compiling data from three landmark contraceptive studies. In this analysis, investigators assessed the efficacy of suppression and the expected recovery rates from various contraceptive regimens. The investigators found with androgen therapy alone the time to suppression to sperm concentration thresholds of 3 million $/ \mathrm{mL}$ and 1 million $/ \mathrm{mL}$ sperm were 10 weeks and 13 weeks, respectively. The time to recovery to a sperm concentration of 20 million $/ \mathrm{mL}$ was found to be 13.6 weeks. Furthermore, after cessation of MHC with an androgen, sperm production was only approximately $85 \%$ of pre-treatment concentrations. In contrast, combination androgen/progestin therapy resulted in faster suppression rates with time to suppression to sperm concentration thresholds of 3 and 1 million/mL sperm being 4 and 5.6 weeks, respectively. However, recovery rates were slower in comparison to androgen-only $\mathrm{MHC}$ as the time to achieve half of a recovery sperm concentration plateau of 17 million/mL being 14.7 weeks. Men treated with combination therapy were also found to have less complete recovery (51).

Recognizing the potential pitfalls prohibiting an MHC regimen from going to market, Liu et al. sought to define the extent of spermatogenic recovery after MHC for appropriate patient counseling. Thus, an analysis of 2,023 men accumulated from data from 30 studies published between 1990 and 2005 was pooled to accomplish this task. The subjects included were primarily Caucasian and Asian (mostly Chinese) men ranging in age from 18-51 years old. Multivariate analysis showed higher rates of recovery with older age, Asian origin, shorter treatment duration, shorter-acting testosterone preparations, higher baseline sperm concentrations, faster suppression of spermatogenesis and lower baseline blood concentrations of LH. It was determined that an Asian or white man treated with longlasting testosterone preparations for one year would need about 4 to 5 months to regain sperm concentration of 20 million/mL. Also, the probability of sperm recovery by 12 months was at least $90 \%$ for concentrations ranging between 3 (98\%) to 20 million/mL (90\%). All men had complete recovery by 24 months. The study also revealed that combined therapy with androgen-progestin regimens could be achieved without the risk of delayed recovery. The study results are primarily limited to Caucasian and Asian men as well as individuals receiving 18 months or less of treatment (52).

\section{Side effects of hormonal contraception}

The most common side effect noted in male hormonal contraceptive studies has been acne. However, the overwhelming majority of studies assessing the efficacy and safety of male hormonal contraception have been limited by the absence of a placebo group. No contraceptive study conducted to date has found an increase in cardiovascular or thromboembolic events $(1,2)$. Investigations have shown that physiological replacement of testosterone using injections, transdermal gels and other delivery systems of testosterone increases lean body mass and decreases fat mass while some of the adverse events associated with the administration of androgens include mood changes, night sweats and headaches (3).

Young et al. studied the effects of weekly injections of $\mathrm{TE}$ on body composition and muscle strength given for the purpose of male contraception in 13 nonathletic men. A $9.6 \%$ increase in fat-free mass along with a $16.2 \%$ decrease in fat mass compared to controls was observed (53).

In a randomized-controlled double-blind study of young, healthy, eugonadal men, Herbst et al. studied the side effect profile of eugondal men were randomized to receive four different combinations of TE and LNG including: weekly $100 \mathrm{mg}$ TE injections plus oral placebo, TE plus 125 micrograms of LNG administered orally and daily, placebo injections plus oral LNG, or placebo injections plus placebo oral pills. The investigators found that testosterone alone led to rapid increases in lean body mass with a 
decrease in fat mass. LNG therapy was found to increase abdominal fat by approximately $4 \%$ thereby potentiating the $4.9 \%$ decrease in adiposity induced by testosterone supplementation (54).

In a study of 50 males, Pelusi et al. studied the effects of TU and norethisterone enanthate (NETE) on body composition and metabolism. Men were separated into five different groups of 10. In four of these groups, each man received $1,000 \mathrm{mg}$ of TU along with $200 \mathrm{mg}$ of NETE given at four different intervals. The remaining group received a placebo. In the group receiving NETE every 8 weeks, BMI significantly increased $(\mathrm{P}=0.02)$ at the end of the treatment period. Furthermore, lean body mass increased significantly in the groups receiving NETE every 6 weeks for 12 weeks and then every 12 weeks $(\mathrm{P}=0.04)$ and NETE every 8 weeks. Overall, along with previous studies proving the contraceptive efficacy of combination regimens of testosterone and progestins, NETE and TU for 48 weeks were found to be well-tolerated without any serious adverse effects (55).

In a study of 36 men with acquired hypogonadism, Katznelson et al. patients treated with $100 \mathrm{mg}$ weekly doses of TE therapy experienced statistically significant increases in lean muscle mass and spinal and trabecular bone mineral densities were observed. Also, a significant decrease in subcutaneous fat was observed (56).

Overall, the aforementioned side effects appear to mild and reversible after cessation of treatment. However, more randomized-control trials are necessary to determine the full adverse profile of MHC. Moreover, the relatively short length of all the trials to date precludes an adequate assessment of cardiovascular or thromboembolic events related to use (23).

\section{Systemic non-hormonal contraception}

There are numerous systemic, non-hormonal therapies that have been proposed and studied as potential male contraceptives. One of the most well-studied therapies is gossypol, a naturally occurring phenol originally extracted from the cotton plant. An early study of the drug administered for the purpose of male contraception found that daily doses of $20 \mathrm{mg}$ were $100 \%$ effective in inducing azoospermia (defined as $<4$ million sperm $/ \mathrm{mL}$ ) within 60 days and could maintain azoospermia with maintenance doses $(57,58)$. The therapy was found to be well-tolerated with investigators noting a trend towards decreasing serum potassium level though no adverse effects associated with hypokalemia were observed (57-59). A later study showed that supplemental potassium and potassium-sparing diuretics actually exacerbated the hypokalemia (59). Further investigations showed that this hypokalemia did not persist (60-62). More recent data has shown that doses of 10-12.5 mg/day are effective in only $60 \%$ of men to reach levels of sperm $<4$ million/mL (60). Reversibility of infertility reaches rates of $51 \%$ a year after stopping and 19\% maintain true azoospermia (60). Overall, gossypol has shown inconsistent effectiveness in suppressing spermatogenesis to levels adequate for contraception. Moreover, poor recovery of spermatogenesis after cessation of therapy makes gossypol a less than ideal candidate for male contraception.

Vitamin A is an essential nutrient for the normal development of sperm in the testis and a natural target for contraception. It has been shown that when receiving vitamin A analogues, such as acitretin or isotretinoin, individuals with oligospermia can have improved sperm counts and sperm morphology $(63,64)$. Mouse models have demonstrated that Vitamin A deficiency as well as absence of the retinoic acid receptor $(R A R)$ gene can result in defects in the spermatogenesis pathway (65-67). Thus, RAR has been identified as a potential target in facilitating male contraception. Oral antagonists of RAR are effective in inducing reversible sterility in mouse models measured by histological changes in the testies $(68,69)$. Moreover, there does not appear to be systemic changes in the mice with regards to blood, or serum chemistry or the hormonal HPG axis (69). As of yet, there are no studies assessing whether RAR antagonists would be effective for contraceptive use in humans.

Sperm are expelled out of the male reproductive tract via sympathetic activity, which make adrenergic receptors another target for contraception. In early studies, phenoxybenzamine (PBZ), an alpha-1-adrenergic antagonist, showed effective inhibition of sperm ejaculation in human trials (70-72). Inhibition of the adrenergic receptors on the musculature of the epididymis and seminal vesicles due to PBZ prevented the normal rhythmic contractions and thus ejaculation (70). A follow-up study showed that PBZ more specifically inhibits the longitudinal muscles and not the circular muscles of the epididymis (72). More recent studies have focused on prazosin and tamsulosin, also alpha-1-adrenergic antagonists, as potential candidates for contraception (73-77). Although, there have been mixed data with prazosin, tamsulosin at doses of $0.8 \mathrm{mg} /$ day, can decrease functional sperm concentration (FSC) to $0 \mathrm{M} / \mathrm{mL}$, compared with $0.4 \mathrm{mg}$ tamuslosin and placebo which 
decreased FSC to $55.95 \pm 6.18$ and $68.13 \pm 1.32 \mathrm{M} / \mathrm{mL}$, respectively (78). The side effects reported in these clinical trials have included ejaculatory discomfort, dizziness, and orthostatic hypotension. There have been no large studies to evaluate the alpha-1-adrenergic antagonists as for potential male contraception.

The use of vasopressin has also been investigated in mouse models, which has been shown to decrease sperm motility, diminish capacitation and acrosome reactions (79). $\mathrm{N}$-butyldeoxynojirimycin (NB-DNJ) is a molecule that showed incredible promise in mouse models but was ineffective in rabbit and human studies (80-82). Adjudin, an indazole-carboxylic acid, has demonstrated reversible and spermatogenesis in rats, rabbits and dogs by disrupting the testis specific anchoring structures between Sertoli cells and developing spermatids (83-85). Animal models have shown promise but data remains limited. I-CDB-4022, an indenopyridine, has shown efficacy with regard to reducing sperm count in mice, rats and cynomolgus monkeys (86-89). The theorized mechanism of action is the induction of apoptosis of immature germ cells through Sertoli cells (88). At high doses it has shown to cause irreversible infertility in rats though reversible when used at lower doses within rats and monkeys $(87,89)$. Nevertheless, further research on I-CDB-4022 is necessary to elucidate is potential for contraception.

Specific molecular targets are an emerging area of research in male contraception. One such target is the epididymal protease inhibitor (eppin). Eppin is a protein specific to the male reproductive tract that promotes normal semen function (90-93). Specifically, interactions of eppin with semenogelin forms a complex that promotes sperm survival in the female reproductive tract (91). Thus, the region in which the complex is adjoined has been identified as a potential molecular target for male contraception (92). Studies looking at immunizing a Macca monkey model against the eppin protein showed $78 \%$ of monkeys (7 out of 9 ) developed high titers $(>1: 10,000)$ of anti-eppin antibodies and developed infertility measured by lack of impregnation of females compared to the control group where five females became impregnated over the same time period [O'Rand]. Infertility was reversed after treatment in $71 \%$ (5 out of 7) of the monkeys [O'Rand]. To date, only animal models exist in exploiting eppin as a potential contraceptive mechanism.

Another target recently studied for contraception is bromodomain testis associated (BRDT), a testis-specific protein $(94,95)$. Found only in the male reproductive tract, the protein is involved in the chromatin remodeling of germ cells, specifically seen in spermatocytes and spermatids. Investigators identified the protein as a potential target for contraception within a mouse by developing a homozygous model at the BRDT gene producing a truncated protein product. The homozygous BRDT-mutant male mice were infertile when compared to a control group of mice by assessing for offspring produced over a 3-month period (94). Subsequent research identified a small molecule, JQ1, that inhibits the BRDT protein and can cause sterility within a healthy mouse. Infertility was reversible upon cessation of treatment. Furthermore, no hormonal changes were observed though a decrease in seminiferous tubule area, sperm number and motility was observed (95).

As non-hormonal therapy becomes more specific at targeting key molecules in the testis and throughout the male reproductive tract, identification of a safe, effective and reversible non-hormonal contraceptive may be on the horizon. At this point, there are several candidates with promise though further investigation is imperative to determine their true potential.

\section{Vas-occlusive devices}

Vas-occlusion, a concept initially introduced the late 1960s, describes a method for inducing infertility in the male by implanting a device into the vas deferens to block sperm transport. Inspired by the challenges of vasovasostomy, Hrdlicka $e t$ al. noted the lack of an effective yet easily reversible method of male contraception, and thus proposed implanting silicone rubber plugs into the vas deferens (96). Over five decades, many attempts at vas-occlusive contraception have been made using various devices such as formed-in-place (FIP) plugs and in situ forming polymers. To date, no vas-occlusive contraceptives have successfully gained regulatory approval.

\section{Reversible inhibition of sperm under guidance (RISUG) and Vasalgel}

An in situ forming polymer, known as RISUG, has been proposed for vas-occlusion (97). In situ forming materials are injected as a liquid and form the gel or implant within the body. RIUSG is a formulation containing the polymer styrene maleic anhydride (SMA) dissolved in an organic solvent (DMSO) (98). When the solution is injected into an aqueous environment, such as the lumen of the vas deferens, the SMA polymer precipitates to form the occlusion. 
Based on the ratio of the monomers (styrene to maleic anhydride), the molecular weight of the SMA co-polymer, and concentration of SMA in DMSO, a partial or complete occlusion may be formed (99).

Clinical trials investigating the use of RISUG have successfully demonstrated no reported pregnancies within a 1-year follow-up period $(100,101)$. However, concerns have arisen given its purported spermicidal mechanism of action. The SMA component of RISUG has been shown to have $\mathrm{pH}$-lowering effects resulting in sperm to undergo damage, degeneration, and morphological changes upon contact with the polymer. When investigated in langur monkeys who underwent the RISUG procedure, the sperm present in the semen had nuclear membrane damage in the acrosome, loss of segmented columns and aberration in the centriole of the neck, degeneration of mitochondrial sheath, and absence of the plasma membrane in the midpiece and tail $(99,102)$. Similarly, in the phase II clinical trial, patients' sperm exhibited morphological abnormalities including bent and coiled tails and amorphous heads. Those sperm successfully able to traverse RISUG were found to be immotile (100).

Safety concerns also exist regarding RISUG's effects on male reproductive organs. In a trial designed to study the chronic histological effects of RISUG in langur monkeys, after 300 days, Sertoli cells showed vacuolization, seminiferous tubules were shrunken, and the spermatids also exhibited vacuolization and degeneration in the nuclear membrane (103).

A similar in situ polymer-based product being developed in the United States is Vasalgel, which comprises the polymer styrene maleic acid dissolved in DMSO rather than the anhydride form used in RISUG. Compared to RISUG, Vasalgel claims no spermicidal effects. Rather, the product is described as a plug impenetrable to sperm (104). In a study of 12 rabbits, Vasalgel produced azoospermia within 29-36 days, which was sustained over a 12 -month period (105). The histology of the rabbit vas deferens post-Vasalgel implantation showed epithelioid macrophages replacing the luminal epithelium, multinucleated giant cells, and granulomatous inflammation (104). In 16 rhesus monkeys, Vasalgel was effective in preventing pregnancies for up to 2 years, though semen analyses were not performed in the subjects (106). As with RISUG, the high viscosity of the Vasalgel solution requires a significant amount of pressure to instill the material in the narrow lumen of the vas deferens with the potential for damage associated with infiltration of Vasalgel into the wall of the vas or under the sheath (106). However, there have been no findings reported of Vasalgel's effects on other genitourinary tissues besides the vas deferens.

Attempts at reversing RISUG and Vasalgel have been achieved by injecting solutions into the lumen of the vas deferens to dissolve the polymer material. RISUG has been reversed with $5 \%$ and $10 \%$ sodium bicarbonate in rabbits and rats, respectively, with fertility being restored within 135 and 150 days $(107,108)$. RISUG has also been shown to be reversible with DMSO in rabbits, although the organic solvent is known to be more toxic than sodium bicarbonate (108). Furthermore, researchers have attempted mechanical means of RISUG reversal in monkeys through percutaneous squeezing, electrical or vibratory stimulation or digital rectal massage of the vas deferens (109). To date, there has been no data reported on reversibility of RISUG in humans.

Vasalgel was similarly reversed in rabbits with sodium bicarbonate (110). In a study conducted by Waller et al., an average of $2-5 \mathrm{~mL}$ of bicarbonate solution was injected into the vas before unrestricted flow was observed. While sperm concentration and motility were similar to baseline levels after reversal, sperm forward progression was significantly lower and normal acrosomes were not observed. After 200 days, the sperm forward progression was merely $15 \%$. Finally, no follow-up studies have been conducted to date assessing fertility and pregnancy rates after Vasalgel reversal.

The surgical approach for both RISUG and Vasalgel has been through traditional vasectomy methods requiring exteriorization of the vas deferens. In these procedures, the vas deferens was elevated using sutures and blunt instruments for stabilization during injection. Once isolated, the vas was injected with $100-120 \mu \mathrm{L}$ of Vasalgel or RISUG using a 24 -gauge $3 / 4$ inches catheter or 22 -gauge needle, respectively, in the cranial direction $(102,110)$.

\section{Percutaneous methods}

There have also been several attempts of achieving vasocclusion with various materials through a percutaneous delivery approach. Rather than exteriorizing the vas deferens, the physicians have injected the occlusive material into the vas through the skin. Usually, this first requires the physician secure the vas deferens to the skin using a traditional or modified vas-clamp, and then puncture the skin and vas deferens simultaneously with a hypodermic needle. There are several advantages of being able to 
perform vas-occlusion percutaneously. The percutaneous method is less invasive and may offer fewer complications such as swelling, hematomas, and infection compared to the surgical method. Furthermore, given the non-surgical approach, men may also be more willing to undergo the procedure and thus, acceptability and usage of the contraceptive would be higher (111).

Percutaneous vas-occlusive methods have seen varying degrees of success. The method was first proposed in 1990 when Zhao reported performing percutaneous delivery of polyurethane elastomer (MPU) plugs into the vas deferens of 12,000 Chinese men, yielding a $98 \%$ azoospermia rate after 1 year (112). However, following the study, there were significant uncertainties about the safety of the MPU material, including potential carcinogenic effects. Thus, researchers began to explore medical-grade silicone. In 1992, percutaneous injection of silicone was performed in 14 Chinese men (113). In this trial, it took 8-9 months before the men had sperm counts below 1 million sperm $/ \mathrm{mL}$, suggesting that sperm were potentially able to traverse around the silicone plugs.

In a study of Indonesian men, Soebadi et al. performed percutaneous delivery of Medical Grade Silicone Rubber (MSR) on 58 patients and a no-scalpel vasectomy (NSV) on 64 patients (114). To secure the vas to the skin, two new clamps were investigated (a 15 -mm oval clamp and $10-\mathrm{mm}$ round clamp). A 21-gauge hypodermic needle was used to puncture the vas, which was then removed and a 23-gauge needle was advanced into the vas. Next, the blunt needle was connected to a large hand-pump applicator. The applicator facilitated injection of the silicone material by turning a hand-wheel. The injection took place over 4 minutes and a 15 -minute wait-time was allocated for hardening of the material before the vas clamp was removed. From a previous ex vivo study of human vas samples, it was determined that 6 turns of the hand wheel (approximately. $153 \mathrm{~mL}$ ) were necessary to form occlusive and durable plugs. In this study, the vas-occlusion group had similar efficacy to the NSV group. By 2 months, 57\% of both groups had azoospermia, and by 6 months, $>98 \%$ of men in both groups were azoospermic. This study also deduced that the 15 -mm oval clamp produced a better plug length and yielded significantly better occlusion rates than the $10-\mathrm{mm}$ round clamp (65\% vs. $33 \%$ ) (114).

Zambon et al. further investigated the use of MSR in 58 Dutch men. Percutaneous vas-occlusion was attempted in 58 men and 50 men received NSV (111). In this study, while 48 out of $50(96 \%)$ men who received vasectomies were azoospermic, only four men (8\%) who received vas-occlusion with MSR were azoospermic after 1 year $(\mathrm{P}<0.001)$. As the rate of azoospermia in men undergoing the percutaneous approach was markedly worse compared to the results of the Soebadi et al. study, the investigators cited the differences in diameter and elasticity of the vas between Indonesian and Dutch men. Nevertheless, significant advantages in safety outcomes were cited favoring the percutaneous method over the NSV method. Men who underwent vas-occlusion reported significantly less pain after the procedure than after vasectomy with visual analogue scale (VAS) scores of 4.4 and 3.1, respectively $(\mathrm{P}=0.02)$. Furthermore, men who underwent vasectomy had significantly more swelling after surgery than vas-occlusion $(\mathrm{P}=0.01)$ as well as hematomas $(\mathrm{P}=0.04)(114)$.

One concern for using FIP materials such as polyurethane and silicone are that large hand-pumps or applicators are required to inject the material and hardeners. In the Soebadi et al. and Zambon et al. studies, one physician was responsible for securing the vas and needle while the other was responsible for holding and turning the applicator. Furthermore, based on available data, at least a 15-minute period was required for the material to fully form inside the vas lumen. The long formation time of the material may be a potential cause for inconsistent plug formation and low efficacy results. The potential for sperm to traverse between the plug and wall of the vas requires further elucidation and research (111). Finally, in the Dutch study, it was determined that the silicone plugs caused extensive fibrosis and tissue reaction around the occlusion site. This suggests simple plug removal for reversal would be difficult, most likely requiring excision and reanastomosis of the vas deferens (111).

There have been other attempts at vas-occlusion using silicone including the Shug, also known as the Intra Vas Device (IVD). This procedure, although not percutaneous, involved inserting two pre-formed silicone plugs into the vas deferens through two punctures, and the plugs were joined by a nylon connecting thread. Preclinical results in primates were promising, with azoospermia over a 7 -month period (115). A small trial of the method in 30 men resulted in complete blockage or immotile sperm in 27 of the 30 men, with the remaining three men exhibiting very low motile sperm counts (116).

Contraline Inc. is a company working on male contraception using image-guided percutaneous delivery to deliver a propriety vas-occlusive hydrogel. Unlike in situ forming polymers, hydrogels may be injected in aqueous 
solvents. Once formed, they are semi-open network systems joined by cross-links, and as such, they can entrap a large fraction of solvent such as water or biological fluid within the pores or interstitial space. The ability to swell and absorb fluid may allow for vas-occlusive hydrogels to alleviate hydrostatic pressure within the vas deferens or epididymis, a phenomenon that often occurs after vasectomy, although this property requires further investigation in vivo (117). Hydrogels, based on their chemistry, may also have tunable properties including hydrophilicity, propensity accumulate fluid, or swell ability, gelation, mechanical strength, porosity, biocompatibility, and reversibility (118). Clinical studies have demonstrated that ultrasound can be used to visualize the vas deferens (119). Furthermore, as the implant is echogenic, or ultrasound-visible, it is postulated that the physician may be able to use ultrasound to guide the injection, image the implant during injection, confirm successful occlusion, and locate the implant prior to reversal (120).

Five decades of research on vas-occlusion has shown that the ideal vas-occlusive contraceptive should have the following properties: be easily administered by a single physician, form instantaneously within the lumen without subsequent migration, effectively block the passage of sperm, be reversible by dissolution or via minor procedure, and have no significant permanent histological effects on the vas deferens, sperm, or genitourinary tissues. If these criteria are fulfilled, vas-occlusive devices have great potential to become the first class of long-lasting, nonhormonal, and reversible male contraceptives.

\section{Conclusions}

The brisk rate in which the world's population is increasing along with the socioeconomic implications of this growth has provided the impetus for improving options for male contraception. The mainstays of male contraception condoms and vasectomy are hindered by poor efficacy and compliance, or challenging reversibility, respectively. The search for alternatives that are as safe, effective and affordable as female methods has resulted in decades of research in the field of male contraception.

The clinical trials investigating the use of androgens or androgen-progestin combinations to facilitate male contraception have shown promise. However, the maturation of this data into a marketable contraceptive product has remained elusive. While the degree of spermatogenesis suppression necessary to achieve infertility has been achieved in several studies, questions remain regarding the speed of induction and the extent of spermatogenesis recovery after cessation of treatment. As surveys have demonstrated that men and women would be receptive to the notion of MHC, the remaining obstacle in bringing MHC to market will be addressing the aforementioned concerns. Current data suggests that spermatogenesis suppression can be achieved as early as three months, or less with combination regimens, which, at the very least, is comparable to the time necessary to prove sterility after vasectomy. Moreover, studies have revealed that the majority of men recover spermatogenesis to concentrations of at least 20 million $/ \mathrm{mL}$ though the time necessary to achieve this level of fertility varies based on the administered regimen. Despite nearly five decades of research in the field of male hormonal contraception, the family planning burden remains with the female partner as men continue to contend with a limited palette of contraceptives options. Occurring in parallel to $\mathrm{MHC}$ research is the growing number of investigations exploring systemic nonhormonal methods and vas deferens occlusion devices. While the prospect of a vas occlusion device appears to be on the horizon, non-hormonal, pharmacologic methods of contraception are limited to animal studies.

The field of male contraception remains a fertile ground as years of research has yet to produce a viable alternative to condoms or vasectomy. However, it is evident that soon men, and their partners, will have more choices at their disposal. Evidence suggests that couples seek to share the responsibility of family planning and contraception. As the impact of unintended pregnancy effects our population on a global level, it is clear that the development of more contraceptive options for men is not just a matter of preference but an imperative.

\section{Acknowledgements}

None.

\section{Footnote}

Conflicts of Interest: Kevin Eisenfrats is the Co-Founder/ Chief Executive Officer of Contraline, Inc. and holds financial stake in the company. Ryan Smith is the Director of Clinical Research for Contraline, Inc. He does not hold any financial ties with company. The other authors have no conflicts of interest to declare.

\section{References}

1. Roth MY, Amory JK. Pharmacologic development of male 
hormonal contraceptive agents. Clin Pharmacol Ther 2011;89:133-6.

2. Roth MY, Amory JK. Beyond the Condom: Frontiers in Male Contraception. Semin Reprod Med 2016;34:183-90.

3. Ilani N, Wang C. Male hormonal contraception: potential risks and benefits. Rev Endocr Metab Disord 2011;12:107-17.

4. Henshaw SK, Singh S, Haas T. The incidence of abortion worldwide. Int Fam Plann Persp 1999;25:S30-8.

5. Wigginton B, Harris ML, Loxton D. Who takes responsibility for contraception, according to young Australian women? Sex Reprod Healthc 2018;15:2-9.

6. Chao JH, Page ST. The current state of male hormonal contraception. Pharmacol Ther 2016;163:109-17.

7. Costantino A, Gava G, Berra M, et al. Advances in Male Hormonal Contraception. Indian J Med Res 2014;140:S58-62.

8. Kanakis GA, Goulis DD. Male contraception: a clinicallyoriented review. Hormones (Athens) 2015;14:598-614.

9. Brannigan RE. Hormonal male contraception - a goal finally realized? Nat Rev Urol 2009;6:409-10.

10. Roth MY, Page ST, Bremmer WJ. Male hormonal contraception: looking back and moving forward. Andrology 2016;4:4-12.

11. Manetti GJ, Honing SC. Update on male hormonal contraception: is the vasectomy in jeopardy? Int J Impot Res 2010;22:159-70.

12. Plana O. Male Contraception: Research, New Methods and Implications for Marginalized Populations. Am J Mens Health 2017;11:1182-9.

13. Dorman E, Bishai D Demand for Male Contraception. Expert Rev Pharmacoecon Outcomes Res. 2012;12:605-13.

14. Johnson D, Sandlow JI. Vasectomy: tips and tricks. Transl Androl Urol 2017;6:704-9.

15. Murdoch FE, Goldberg E. Male contraception: another Holy Grail. Bioorg Med Chem Lett 2014;24:419-24.

16. Handelsman DJ. Male contraception. De Groot LJ, Chrousos G, Dungan K, et al., editors. Endotext [Internet]. South Dartmouth (MA): MDText.com, Inc.; 2000. Available online: https://www-ncbi-nlm-nih-gov.proxy01. its.virginia.edu/books/NBK279094

17. Singh G. Vasectomy, its consequences. IRCS J Med Sci 1979;7:488-91.

18. Hoesl CE, Saad F, Poppel M, et al. Reversible, nonbarrier male contraception: status and prospects. Eur Urol 2005;48:712-22.

19. Liu PY, Swerdloff RS, Wang C. Recent methodological advances in male hormonal contraception. Contraception 2010;82:471-5.
20. Heinemann K, Saad F, Wiesemes M, et al. Attitudes toward male fertility control: results of a multinational survey on four continents. Hum Reprod 2005;20:549-56.

21. Dorman E, Perry B, Polis CB, et al. Modeling the impact of novel male contraceptive methods on reductions in unintended pregnancies in Nigeria, South Africa and the United States. Contraception 2018;97:62-9.

22. Glasier AF, Anakwe R, Everington D, et al. Would women trust their partners to use a male pill? Hum Reprod 2000;15:646-9.

23. Zitzmann M. Would male hormonal contraceptives affect cardiovascular risk?. Asian J Androl 2018;20:145-8.

24. Behre HM, Zitzmann M, Anderson RA, et al. Efficacy and safety of an injectable combination hormonal contraceptive for men. J Clin Endocrinol Metab 2016;101:4779-88.

25. Liu PY and McLachlan RI. Male hormonal contraception: so near and yet so far. J Clin Endocrinol Metab 2008;93:2474-6.

26. Steinberger E. Current status of research on hormonal contraception in the male. Res Front Fertil Regul 1980;1:1-12.

27. Neaves WB. Leydig cells. Contraception 1975;11:571-606.

28. Chao J, Page ST, Anderson RA. Male contraception. Best Pract Res Clin Obstet Gynaecol 2014;28:845-57.

29. Wang C, Festin MP, Swerdloff RS. Male Hormonal Contraception: Where Are We Now? Curr Obstet Gynecol Rep 2016;5:38-47.

30. World Health Organization Task Force for the Regulation of Male Fertility. Contraceptive efficacy of testosterone-induced azoospermia in normal men. Lancet 1990;336:955-9.

31. World Health Organization Task Force on Methods for the Regulation of Male Fertility. Contraceptive efficacy of testosterone-induced azoospermia and oligozoospermia in normal men. Fertil Steril 1996;65:821-9.

32. Aaltonen P, Amory JK, Anderson RA, et al. 10th Summit Meeting consensus: recommendations for regulatory approval for hormonal male contraception. J Androl 2007;28:362-3.

33. Sukcharoen N, Aribarg A, Krianogsinyos R, et al. Contraceptive efficacy and adverse effects of testosterone enanthate in Thai men. J Med Assoc Thai 1996;79:767-73.

34. MacIndoe JH, Perry PJ, Yates WR et al. Testosterone suppression of the HPT axis. J Investig Med 1997;45:441-7.

35. Gu YQ, Wang XH, Xu D, et al. A multicenter contraceptive efficacy study of injectable testosterone undecanoate in healthy Chinese men. J Clin Endocrinol Metab. 2003;88:562-8. 
36. Gu Y, Liang X, Wu W, et al. Multicenter contraceptive efficacy trial of injectable testosterone undeconoate in Chinese men. J Clin Endocrinol Metab 2009;94:1910-5.

37. Nieschlag E, Vorona E, Wenk $M$ et al. Hormonal male contraception in men with normal and subnormal semen parameters. Int J Androl 2011;34:556-67.

38. Nieschlag E. Clinical trials in male hormonal contraception. Contraception 2010;82:457-70.

39. McLachlan RI. Male hormonal contraception: a safe, acceptable and reversible choice. Med J Aust 2000;172:254-5.

40. Patel DP, Chandrapal JC and Hotaling JM. Hormone Based Treatments in Subfertile Males. Curr Urol Rep 2016;17:56.

41. Zitzmann M, Rohayem J, Raidt J, et al. Impact of various progestins with or without transdermal testosterone on gonadotropin levels for non-invasive hormonal male contraception: a randomized clinical trial. Andrology 2017;5:516-26.

42. Attardi BJ, Koduri S, Hild SA. Relative progestational and androgenic activity of four progestins used for male hormonal contraception assessd in vitro in relation to their ability to suppress LH secretion in the castrate male rat. Mol Cell Endocrinol 2010;328:16-21.

43. Meriggiola MC, Bremner WJ, Costantino A, et al. Low dose of cyproterone acetate and testosterone enanthate for contraception in men. Hum Reprod 1998;13:1225-9.

44. Büchter D, von Eckardstein S, von Eckardstein A, et al. Clinical trial of transdermal testosterone and oral levonorgestrel for male contraception. J Clin Endocrinol Metab 1999;84:1244-9.

45. Martin CW, Riley SC, Everington D, et al. Dose-finding study of oral desogestrel with testosterone pellets for suppression of the pituitary-testicular axis in normal men. Hum Reprod 2000;15:1515-24.

46. Turner L, Conway AJ, Jimenez M, et al. Contraceptive efficacy of a depot progestin and androgen combination in men. J Clin Endocrinol Metab 2003;88:4659-67.

47. Hay CJ, Brady BM, Zitzmann M, et al. A multicenter phase IIB study of novel combination of intramuscular androgene (testosterone decanoate) and oral progestogen (Etonogestrel) for male hormonal contraception. J Clin Endocrinol Metab 2005;90:2042-9.

48. Mommers E, Kersemaekers WM, Elliesen J, et al. Male hormonal contraception: a double-blind, placebo-controlled study. J Clin Endocrinol Metab 2008;93:2572-80.

49. Roth MY, Ilani N, Wang C et al. Characteristics associated with suppression of spermatogenesis in a male hormonal contraceptive trial using testosterone and Nestorone gels.
Andrology 2013;1:899-905.

50. Page ST, Amory JK, Anawalt BD, et al. Testosterone gel combined with depomedroxyprogesterone acetate is an effective male hormonal contraceptive regimen and is not enhanced by the addition of a GnRH antagonist. J Clin Endocrinol Metab 2006;91:4374-80.

51. Ly LP, Liu PY, Handelsman DJ. Rates of suppression and recovery of human sperm output in testosteronebased hormonal contraceptive regimens. Hum Reprod 2005;20:1733-40.

52. Liu PY, Swerdloff RS, Christenson PD, et al. Rate, extent and modifiers of spermatogenic recovery after hormonal male contraception: an integrated analysis. Lancet 2006;367:1412-20.

53. Young NR, Baker HW, Liu G, et al. Body composition and muscle strength in healthy men receiving testosterone enanthate for contraception. J Clin Endocrinol Metab 1993;77:1028-32.

54. Herbst KL, Anawalt BD, Amory JK, et al. The male contraceptive regimen of testosterone and levonorgestrel significantly increases lean mass in healthy young men in 4 weeks, but attenuates a decrease in fat mass induced by testosterone alone. J Clin Endocrinol Metab 2003;88:1167-73.

55. Pelusi C, Constantino A, Cerpolini S, et al. A placebocontrolled, randomized clinical trial using testosterone undecanoate with injectable norethisterone enanthate: effect on anthropometric, metabolic and biochemical parameters. Int J Androl 2011;34:548-55.

56. Katznelson L, Finkelstein JS, Schoenfeld DA, et al. Increase in bone density and lean body mass during testosterone administration in men with acquired hypogonadism. J Clin Endocrinol Metab 1996;81:4358-65.

57. Liu GZ. Clinical Study of Gossypol as a Male Contraceptive. Reproduccion 1981;5:189-93.

58. Liu GZ, Lyle K, Cao J. Clinical trial of gossypol as a male contraceptive drug Part I Efficacy Study. Fertil Steril 1987;48:459-61.

59. Liu GZ, Lyle K. Clinical trial of gossypol as a male contraceptive drug Part II Hypokalemia Study. Fertil Steril 1987;48:462-5.

60. Coutinho EM, Athayde C, Atta G, et al. Gossypol blood levels and inhibition of spermatogenesis in men taking gossypol as a contraception. A multicenter, international, dose-finding study. Contraception 2000;61:61-7.

61. Gu ZP, Mao B, Wang Y, et al. Low dose gossypol for male contraception. Asian J Androl 2000;2:283-7.

62. Adekunle AO, Arowojoli A, Adejumon C, et al. Seminal plasma zinc levels in users of gossypol. Afr J Med Med Sci 
1999;28:1-4.

63. Parsch EM, Ruzicka T, Przybilla B, et al. Andrological investigations in men treated with acitretin (Ro 10-1670). Andrologia 1990;22:479-82.

64. Amory JK, Ostrowski K, Gannon J, et al. Isotretinoin administration improves sperm production in men with infertility from oligoasthenozoospermia: a pilot study. Andrology 2017;5:1115-23.

65. Boucheron-Houston C, Canterel-Thouennon L, Lee T, et al. Long-term vitamin A deficiency induces alteration of adult spermatogenesis and spermatogonial differentiation: direct effect on spermatogonial gene expression and indirect effects via somatic cells. J Nutr Biochem 2013;24:1123-35.

66. Chung SS, Wang Z, Wolgemuth D. Male Sterility in mice lacking retinoic acid receptor alpha involves specific abnormalities in spermiogenesis. Differentiation 2005;73:188-98.

67. Doyle TJ, Braun K, McLean D, et al. Potential functions of retinoic acid receptor A in sertoli cells and germ cells during spermatogenesis. Ann N Y Acad Sci 2007;1120:114-30.

68. Chung SS, Cuellar R, Wang X, et al. Pharmacological Activity of Retinoic Acid Receptor Alpha-selective antagonists in vitro and in Vivo. ACS Med Chem Lett 2013;4:446-50.

69. Chung SS, Wang X, Roberts S, et al. Oral administration of a retinoic Acid receptor antagonist reversibly inhibits spermatogenesis in mice. Endocrinology 2011;152:2492-502.

70. Kedia KR, Persky L. Effect of phenoxybenzamine (dibenzyline) on sexual function in man. Urology 1981;18:620-1.

71. Homonnai ZT, Shilon M, Paz G. Phenoxybenzamine -- an effective male contraceptive pill. Contraception 1984;29:479-91.

72. Amobi NI, Smith I. Differential inhibition in the human vas deferens by phenoxybenzamine: a possible mechanism for its contraceptive action. J Reprod Fertil 1995;103:215-21.

73. Kjaergaard N, Kjaergaard B, Lauritsen J. Prazosin, an adrenergic blocking agent inadequate as male contraceptive pill. Contraception 1988;37:621-9.

74. Ratnasooriya WD, Wadsworth R. Impairment of fertility of male rats with prazosin. Contraception 1990;41:441-7.

75. Hellstrom WJ, Wang R, Peteron C, et al. Effects of alprostadil and prazosin on motility, viability and membrane integrity of human sperm. J Urol 1998;159:1559-62.

76. Ratnasooriya WD, Wadsworth R. Tamsulosin, a selective alpha 1-adrenoceptor antagonists, inhibits fertility of male rats. Andrologia 1994;26:107-10.

77. Hellstrom WJ, Sikka S. Effects of alfuzosin and tamsulosin on sperm parameters in healthy men: results of a shortterm, randomized, double-blind, placebo-controlled, crossover study. J Androl 2009;30:469-74.

78. Wang J, Zhao Y, Jiang S, et al. Assessment of tamsulosin as a potential male contraceptive in health volunteers. Urology 2012;80:614-7.

79. Kwon WS, Park Y, Kim Y, et al. Vasopressin effectively suppresses male fertility. PloS One 2013;8:e54192.

80. van der Spoel AC, Jeyakuma M, Butters T, et al. Reversible infertility in male mice after oral administration of alkylated imino sugars: a nonhormonal approach to male contraception. Proc Natl Acad Sci 2002;99:17173-8.

81. Walden CM, Butters T, Dwek R, et al. Long-term non-hormonal male contraception in mice using N-butyldeoxynojirimycin. Hum Reprod 2006;21:1309-15.

82. Gupta VJ, Hild S, Jakkaraj S, et al. In Vitro Versus In Vivo Effects of NB-DGJ and NB DNJ as lead compounds for development of Non-Hormonal Reversible Oral Male Contraceptives. Biology of Reproduction 2010;83:679.

83. Mok KW, Mruk D, Lie P, et al. Adjudin, a potential male contraceptive, exerts its effects locally in the seminiferous epithelium of mammalian testes. Reproduction 2011;141:571-80.

84. Su L, Cheng C, Mruk D. Adjudin-mediated Sertoli-germ cell junction disassembly affects sertoli cell barrier function in vitro and in vivo. Int J Biochem Cell Biol 2010;42:1864-75.

85. Kopera IA, Su L, Bilinska B, et al. An in vivo study on adjudin and blood-testis barrier dynamics. Endocrinology 2009;150:4724-33.

86. Cook CE, Wani M, Jump J, et al. Structure-activity studies of 2,3,4,4a,5,9b-hexahydroindeno[1,2-c]pyridines as antispermatogenic agents for male contraception. J Med Chem 1995;38:753-63.

87. Hild SA, Meistrich M, Blye R, et al. Lupron depot prevention of antispermatogenic/antifertility activity of the indenopyrifine, CDB-4022, in the rat. Biol Reprod 2001;65:165-72.

88. Hild SA, Reel J, Larner J, et al. Disruption of spermatogenesis and sertoli cell structure and function by the indenopyridine CDB-4022 in rats. Biol Reprod 2001;65:1771-9.

89. Hild SA, Marshall G, Attardi B, et al. Development of I-CDB-4022 as a nonsteroidal male oral contraceptive: induction and recovery from severe oligospermia in the adult male cynomolgus monkey (Macaca fascicularis). Endocrinology 2007;148:1784-96. 
90. Wang Z, Widgren E, Sivashanmugam P, et al. Association of Eppin with semenogelin on human spermatozoa. Biol Reprod 2005;72:1064-70.

91. Silva EJ, Hamil K, Richardson R, et al. Characterization of EPPIN's semenogelin I binding site: a contraceptive drug target. Biol Reprod 2012;87:56.

92. O'rand MG, Widgren E, Sivashanmugam P, et al. Reversible immunocontraception in male monkeys immunized with eppin. Science 2004;306:1189-90.

93. Chen Z, He W, Liang Z, et al. Protein prime-peptide boost as a new strategy induced and Eppin dominant B-cell epitope specific immune response and suppressed fertility. Vaccine 2009;27:733-40.

94. Shang E, Nickerson H, Wen D, et al. The first bromodomain of Brdt, a testis-specific member of the BET sub-family of double-bromodomain-containing proteins, is essential for male germ cell differentiation. Development 2007;134:3507-15.

95. Matzuk MM, McKeown M, Filippakopoulos P, et al. Small-molecule inhibition of BRDT for male contraception. Cell 2012;150:673-84.

96. Hrdlicka JG, Schwartzman W, Hasel K, et al. New approaches to reversible seminal diversion. Fertil Steril 1967;18:289-96.

97. Misro M, Guha S, Singh H, et al. Injectable non-occlusive chemical contraception in the male. Contraception 1979;20:467-73.

98. Guha S. Contraceptive for use by a male. US 5,488,075. 1994. Available online: http://patft.uspto.gov/netacgi/nphParser? Sect $1=$ PTO $2 \&$ Sect $2=$ HITOFF $\& \mathrm{p}=1 \& \mathrm{u}=\% 2$ Fneta html\%2FPTO\%2Fsearch-bool.html\&r=3\&f=G\&l=50\&co $1=A N D \& d=P T X T \& s 1=\% 22 U S+5,488,075 \% 22 \& O S=" U$ $\mathrm{S}+5,488,075$ "\&RS="US+5,488,075"

99. Lohiya, NK, Alam K, Hussain M, et al. RISUG: an intravasal injectable male contraceptive. Indian J Med Res 2014;140:S63-72.

100. Guha SK, Singh G, Ansari S, et al. Phase II clinical trial of a vas deferens injectable contraceptive for the male. Contraception 1997;56:245-50.

101. Chaki SP, Das H, Misro M. A short-term evaluation of semen and accessory sex gland function in Phase III trial subjects receiving intravasal contraceptive RISUG. Contraception 2003;67:73-8.

102.Lohiya, NK, Manivannan B, Mishra P. Ultrastructural changes in the spermatozoa of langur monkeys presbytis entellus after vas occlusion with styrene maleic anhydride. Contraception 1998;57:125-32.

103.Mishra PK, Manivannan B, Pathak N, et al. Status of spermatogenesis and sperm parameters in langur monkeys following long-term vas occlusion with styrene maleic anhydride. J Androl 2003;24:501-9.

104. DePinto J, Templer D, Nikitenko A, et al. Compositions and methods relating to an occlusive polymer hydrogel. US 9,861,515 B2. 2014. Available online: http://patft. uspto.gov/netacgi/nph-Parser?Sect1=PTO2\&Sect2=HIT OFF\&p=1\&u=\%2Fnetahtml\%2FPTO $\% 2$ Fsearch-adv.ht $\mathrm{m} \& \mathrm{r}=1 \& \mathrm{f}=\mathrm{G} \& \mathrm{l}=50 \& \mathrm{~d}=\mathrm{PTXT} \& \mathrm{~S} 1=\% 22 \mathrm{US}+9,861,515+\mathrm{B}$ $2 \% 22 \& \mathrm{OS}=$

105. Waller D, Bolick D, Lissner E, et al. Azoospermia in rabbits following an intravas injection of Vasalgel TM. Basic Clin Androl 2016;26:6.

106. Colagross-Schouten A, Lemoy MJ, Keesler R, et al. The contraceptive efficacy of intravas injection of VasalgelTM for adult male rhesus monkeys. Basic Clin Androl 2017;27:4.

107. Koul V, Srivastav A, Guha S. Reversibility with sodium bicarbonate of styrene maleic anhydride, an intravasal injectable contraceptive, in male rats. Contraception 1998;58:227-31.

108. Ansari AS, Ayesha B, Krithika B, et al. Contraception with RISUG® and functional reversal through DMSO and NaHCO3 in male rabbits. Asian J Androl 2017;19:389-95.

109.Lohiya NK, Manivannan B, Mishra P, et al. Preclinical evaluation for noninvasive reversal following long-term vas occlusion with styrene maleic anhydride in langur monkeys. Contraception 2005;71:214-26.

110. Waller D, Bolick D, Lissner E, et al. Reversibility of VasalgelTM male contraceptive in a rabbit model. Basic Clin Androl 2017;27:8.

111.Zambon JV, Barone M, Pollack A, et al. Efficacy of percutaneous vas occlusion compared with conventional vasectomy. BJU Int 2000;86:699-705.

112.Zhao SC. Vas deferens occlusion by percutaneous injection of polyurethane elastomer plugs: clinical experience and reversibility. Contraception 1990;41,453-9.

113.Zhao SC, Zhang S, and Yu R. Intravasal injection of formed-in-place silicone rubber as a method of vas occlusion. Int. J. Androl 1992;15:460-4.

114. Soebadi DM, Gardjito W, Mensink H. Intravasal injection of formed-in-place medical grade silicone rubber for vas occlusion. Int. J. Androl 1995;18:45-52.

115.Zaneveld LJ, Burns J, Beyler S, et al. Development of a potentially reversible vas deferens occlusion device and evaluation in primates. Fertil Steril 1988;49:527-33.

116.Zaneveld L, De Castro M, Faria G, et al. The soft, hollow plug (Shug): a potentially reversible vas deferens occlusive 
device. In: Rajalakshmi M, Griffin PD, editors. Male contraception: present and future. New Delhi: New Age Int (P) Ltd., 1999:293-307.

117.Johnson AL, Howards S. Intratubular hydrostatic pressure in testis and epididymis before and after vasectomy. Am J Physiol 1975;228:556-64.

118.Majee SB. Introductory Chapter: An Overview of Hydrogels, Emerging Concepts in Analysis and Applications of Hydrogels, Dr. Sutapa Biswas Majee (Ed.), InTech, DOI: 10.5772/64302. 2016. Available online:

Cite this article as: Khourdaji I, Zillioux J, Eisenfrats K, Foley $\mathrm{D}$, Smith R. The future of male contraception: a fertile ground. Transl Androl Urol 2018;7(Suppl 2):S220-S235. doi: 10.21037/ tau.2018.03.23 https://mts.intechopen.com/books/emerging-conceptsin-analysis-and-applications-of-hydrogels/introductorychapter-an-overview-of-hydrogels

119. Middleton WD, Nirvikar D, Naughton C, et al. Highresolution sonography of the normal extrapelvic vas deferens. J Ultrasound Med 2009;28:839-46.

120.Herr J, Klibanov A, Eisenfrats K. Compositions and methods for vas-occlusive contraception and reversal thereof. WO2017083753A1. 2015. 